\title{
Targeting P53 as a Future Strategy to Overcome Gemcitabine Resistance in Biliary Tract Cancers
}

\author{
Chiao-En Wu ${ }^{1}\left(\right.$, Yi-Ru Pan ${ }^{2}{ }^{\circledR}$, Chun-Nan Yeh ${ }^{2, *}$ and John Lunec ${ }^{3, *}$ \\ 1 Division of Hematology-Oncology, Department of Internal Medicine, Chang Gung Memorial Hospital \\ at Linkou, Chang Gung University College of Medicine, Taoyuan 333, Taiwan; jiaoen@gmail.com \\ 2 Department of General Surgery and Liver Research Center, Chang Gung Memorial Hospital, Linkou branch, \\ Chang Gung University, Taoyuan 333, Taiwan; panyiru0331@gmail.com \\ 3 Newcastle University Cancer Centre, Bioscience Institute, Medical Faculty, Newcastle University, \\ Newcastle upon Tyne NE2 4HH, UK \\ * Correspondence: yehchunnan@gmail.com (C.-N.Y.); john.lunec@newcastle.ac.uk (J.L.); \\ Tel.: +886-3-3281200 (ext. 3219) (C.-N.Y.); +44-(0)-191-208-4420 (J.L.); Fax: +886-3-3285818 (C.-N.Y.); \\ +44-(0)-191-208-4301 (J.L.)
}

Received: 28 September 2020; Accepted: 21 October 2020; Published: 23 October 2020

check for updates

\begin{abstract}
Gemcitabine-based chemotherapy is the current standard treatment for biliary tract cancers (BTCs) and resistance to gemcitabine remains the clinical challenge. TP53 mutation has been shown to be associated with poor clinicopathologic characteristics and survival in patients with BTCs, indicating that p53 plays an important role in the treatment of these cancers. Herein, we comprehensively reviewed previous BTC preclinical research and early clinical trials in terms of p53, as well as novel p53-targeted treatment, alone or in combination with either chemotherapy or other targeted therapies in BTCs. Preclinical studies have demonstrated that p53 mutations in BTCs are associated with enhanced gemcitabine resistance, therefore targeting p53 may be a novel therapeutic strategy for treatment of BTCs. Directly targeting mutant p53 by p53 activators, or indirectly by targeting cell cycle checkpoint proteins (Chk1, ataxia telangiectasia related (ATR), and Wee1) leading to synthetic lethality, may be potential future strategies for gemcitabine-resistant p53 mutated BTCs. In contrast, for wild-type p53 BTCs, activation of p53 by inhibition of its negative regulators (MDM2 and wild-type p53-induced phosphatase 1 (WIP1)) may be alternative options. Combination therapies consisting of standard cytotoxic drugs and novel small molecules targeting p53 and related signaling pathways may be the future key standard approach to beat cancer.
\end{abstract}

Keywords: p53; gemcitabine resistance; biliary tract cancer

\section{Current Treatment for Biliary Tract Cancers (BTCs): Chemotherapy, Targeted Therapy, and Immunotherapy}

Biliary tract cancers (BTCs) including intrahepatic cholangiocarcinoma (iCCA), extrahepatic cholangiocarcinoma (eCCA), gallbladder cancer, and ampullary cancer are a group of relatively rare cancers arising from the epithelium of the biliary tract [1-4] and have aggressive biological behavior, as they are diagnosed at an advanced stage with poor prognosis and have a high recurrence rate after primary surgery $[5,6]$. Gemcitabine and cisplatin have been the standard treatments in first-line chemotherapy since the ABC-02 trial was published in 2010 [7]. Clinical trials have evaluated molecular targeted therapies in combination with chemotherapy; however, none of the completed phase III trials [8-11] and phase II studies [12-15] have demonstrated significant improvement in progression-free survival (PFS) and overall survival (OS) in patients with advanced BTCs [16]. Real word experience has confirmed the feasibility and safety of gemcitabine and cisplatin in advanced BTCs $[6,17]$. 
With the development of comprehensive genetic profiling by next generation sequencing (NGS), alterations of isocitrate dehydrogenase genes (IDH1, IDH2) and fibroblast growth factor receptors (FGFR1, FGFR2, FGFR3) were found in iCCA and targeting such genetic alterations has become a novel therapeutic strategy in iCCA [18,19]. Recently, pemigatinib (Pemazyre), a FGFR inhibitor, has demonstrated activity in previously treated, unresectable locally advanced or metastatic CCA with FGFR2 fusions or rearrangements [20]. Such FGFR2 alternations account for 15\% of iCCA [19] and are not found in other BTCs, limiting its general application in BTCs. In addition, pemigatinib is approved to be used for chemotherapy-treated CCA patients, so chemotherapy is still the first-line standard treatment for iCCA patients.

Although immune checkpoint inhibitors (ICIs) showed limited efficacy in unselected patents [21], a number of biomarker-guided immunotherapy studies are currently recruiting for ongoing trials [22]. Pembrolizumab was approved for treatment of a variety of advanced microsatellite instability-high (MSI-H) or deficient mismatch repair (dMMR) solid tumors (including BTC) [23] in 2017, but MSI-H or dMMR rarely occur in BTCs, including iCCA [24,25]. Recently, pembrolizumab was approved for treatment of tumor mutation burden-high (TMB-H) solid tumors, which is defined as $\geq 10$ mutations/megabase (mut/Mb) assessed by FoundationOneCDx assay. Similar to MSI-H/dMMR, TMB-H rarely happens in BTCs, limiting the utility of ICIs in BTCs. Combination trials of ICIs and chemotherapy are ongoing to explore the potential for future application in BTCs.

Therefore, chemotherapy is still the mainstay of treatment in advanced BTCs. In CCA patients with FGFR2 fusion or rearrangement, pemigatinib is a late-line treatment option. The use of ICIs such as pembrolizumab is limited to CCA patients with MSI-H/dMMR or TMB-H.

\section{Introduction to $\mathrm{p} 53$ in Cancer}

In 1979, p53 was originally discovered by several groups as the host tumor protein targeted by the large tumor antigen of SV40 DNA tumor virus [26-30]. The TP53 gene, which encodes p53, was generally considered to be an "oncogene" before the mid-1980s [31-33], when sequencing of p53 cDNA clones revealed that some of them carried mutations that were comparable to the sequence of murine wild-type p53 derived from normal tissues [34,35]. It became clear that p53 mutations are frequently present in tumor-derived cell lines [34] and it was found that mouse tumor derived mutant (MUT) p53 could indeed promote cell transformation and survival but wild-type (WT) p53 did not. Deletion mapping studies accompanied by DNA sequencing demonstrated a frequent two-hit p53 allele inactivation mechanism in human tumors and strongly indicated that p53 works as a tumor suppressor [36]. The observation that transformation of cultured cells could be repressed by overexpression of WT p53 confirmed its tumor suppressor role [37]. Further confirmation of the tumor suppressor role of p53 and the two-hit inactivation mechanism came from the demonstration of mono-allelic germline TP53 mutations in Li-Fraumeni familial cancer predisposition syndrome, and the second hit inactivation was evident in the tumors of the affected Li-Fraumeni patients [38].

In the early 1990s, p53 was found to be a transcription factor [39] that can bind tightly to a specific DNA consensus sequence [40]. The abilities to bind to specific sequences and transactivate particular genes distinguishes WT p53 from all cancer-associated p53 mutants. CDKN1A encoding the cyclin-dependent kinase inhibitor p21 [41] and the proapoptotic $B A X$ gene [42] were found to be transactivated by p53. Subsequently, a number of additional p53 transcriptionally targeted genes have been identified, most of which encode proteins that are intimately involved in apoptosis or in control of cell cycle progression. In addition, two of the transcriptionally targeted genes, MDM2 and PPM1D, have an autoregulatory feedback role to regulate $\mathrm{p} 53$.

The MDM2 protein, the most important protein directly interacting with p53, was discovered in 1992. MDM2, an E3 ubiquitin ligase, was shown to bind to p53 tightly and inhibit p53 transcriptional activity [43] as well as promoting the ubiquitylation and subsequent proteasomal degradation of p53 [44]. MDMX (MDM4 in the mouse) was discovered as a paralogue of MDM2 in 1996, which can form heterodimers with MDM2 to augment MDM2 activity and contribute to p53 degradation but has 
no measurable intrinsic E3 ligase activity $[45,46]$. The intimate relationship between MDM2 and p53 was demonstrated by gene knockout studies in mice. Knockout of the MDM2 gene was found to be embryonically lethal but could be rescued by additional knockout of the mouse p53 gene [47].

Activation of p53 occurs in response to cellular stress, particularly as a consequence of DNA damage response (DDR), such as induced by gemcitabine. The DDR signaling results in phosphorylation of p53 and MDM2, which prevents MDM2 from binding to p53. This allows levels of the p53 protein to increase and activates its function as a transcription factor $[48,49]$ to drive the expression of p53 target genes, which execute the appropriate cellular responses, including DNA repair, altered metabolism, cell cycle arrest, or apoptosis and senescence [50]. The TP53 gene is one of the most frequently mutated genes in human cancer [51] and has been found to be either mutated or the p53 protein functionally inactivated in most human cancers [52,53]. Homozygous mutation and/or deletion of TP53 results in loss of WT p53 tumor suppressor function. However, some of the point missense mutations have also been shown to have dominant oncogenic functions (gain-of-function mutations) that can override WT p53 from a remaining WT TP53 allele, via binding to other transcription factors that transactivate genes associated with tumor survival and drug resistance [54] (Figure 1).
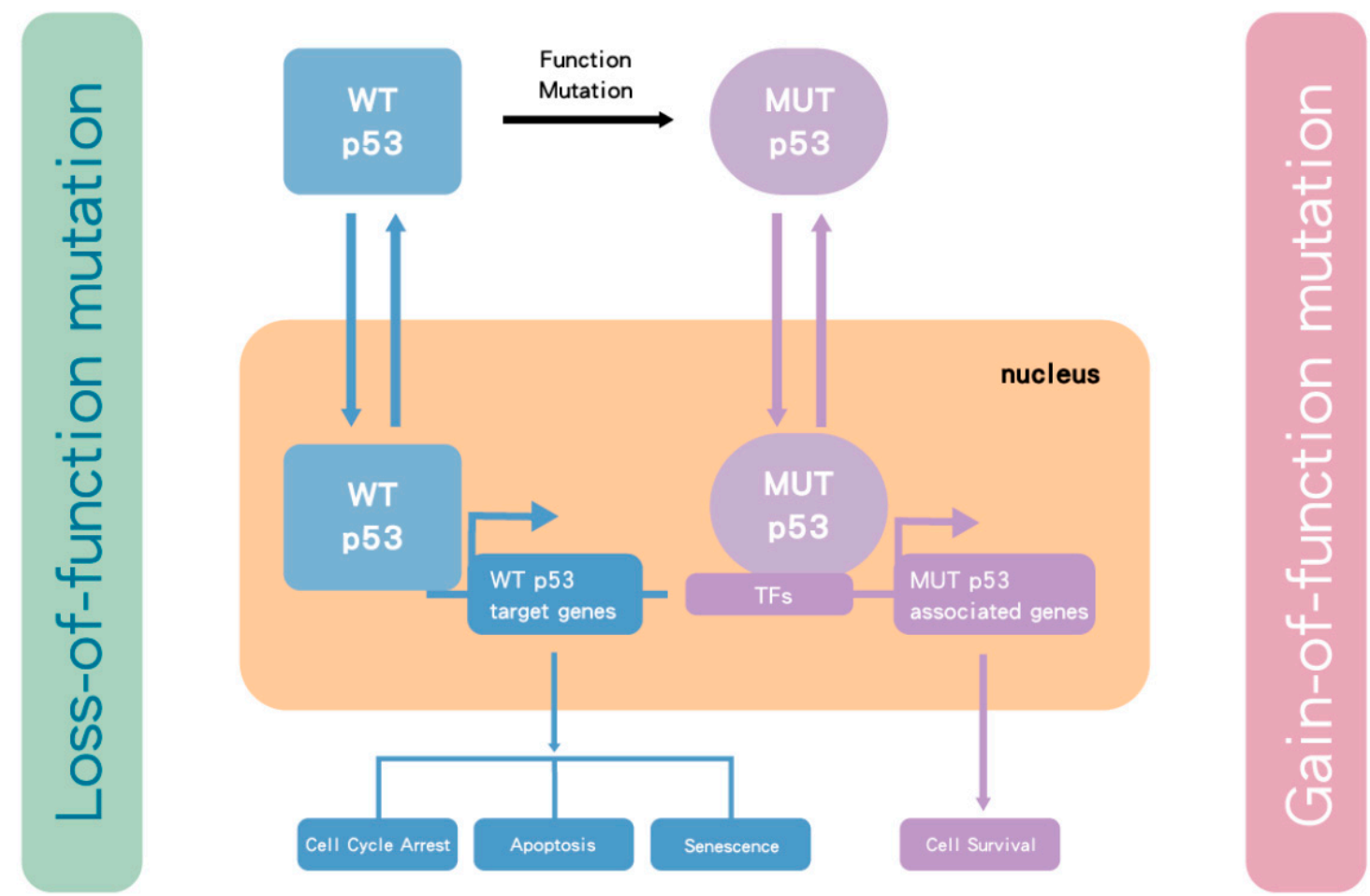

Figure 1. The influence of TP53 mutation in cancer cells. p53 is a transcription factor that transactivates downstream genes responsible for cell cycle arrest, apoptosis and cell senescence. Once p53 becomes mutated (MUT), it loses wild-type (WT) p53 function. In some cases, the mutant form selectively accumulates due to loss of binding to MDM2. As p53 functions as a tetramer, the mutant and functionally defective form then dominates over the lower number of wild-type p53 protein molecules from the remaining normal allele. However, for the most part, TP53 behaves as a classical tumor suppressor gene and both alleles need to be inactivated by a combination of mutation and/or deletion. Nevertheless, some mutant forms of p53 bind to transcription factors (TFs), which transactivate genes responsible for tumor survival and drug resistance. Taken together, MUT p53 enhances tumor growth. 


\section{3. p53 in BTCs}

\section{1. p53 Mutation in BTCs}

In most cancers, TP53 is one of the top frequently mutated genes; however, iCCA have p53 mutations only in a minority of cases (23\%) [18], indicating that 77\% of iCCA have WT p53, which nevertheless may be repressed by its negative regulators. In contrast, the frequency of TP53 mutations in subtypes of BTC, eCCA and GB has been reported to have a higher frequency of TP53 mutation than iCCA (Figure 2B). Overall, TP53 mutations are present in around 32\% of all BTCs (Figure 2C). TP53 mutations frequently occur in the DNA binding domain of p53, resulting in loss of transcriptional transactivation function (Figure 2D).

A

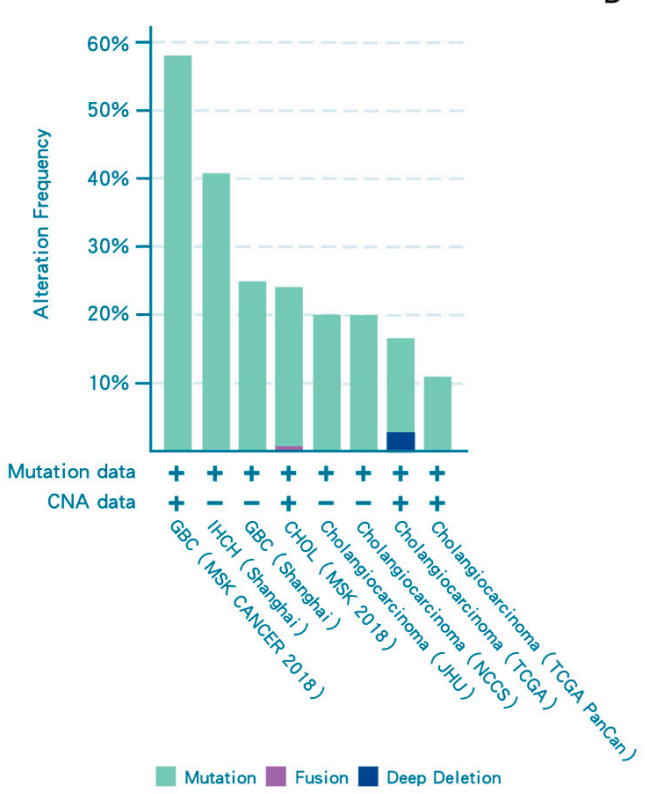

C
Study of origin

TP53

Genetic Alteration

Study of origin

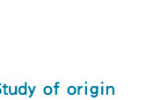

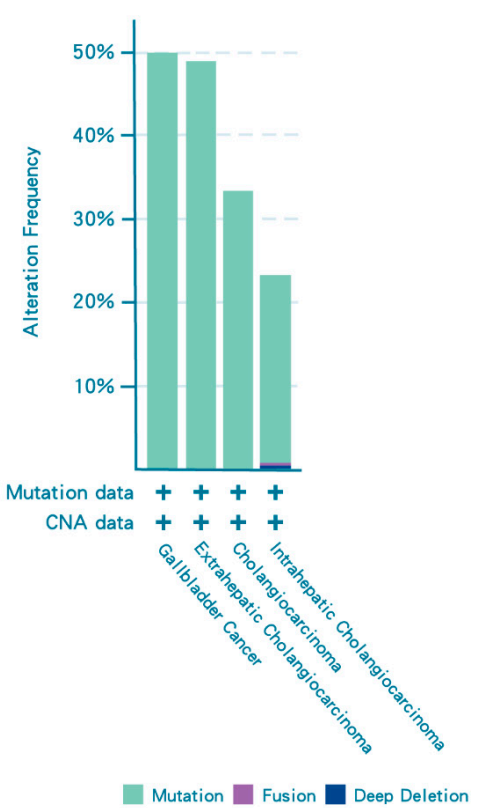

IInframe Mutation (putative driver) $\quad$ Missense Mutation (putative driver) ITruncating Mutation (putative driver) II Fusion

| Deep Deletion || No alterations - Not profiled

|Cholangiocarcinoma (MSK, Clin Cancer Res 2018) | Cholangiocarcinoma (National Cancer Centre of Singapore, Nat Genet 2013)

|Cholangiocarcinoma (National University of Singapore, Nat Genet 2012) \Cholangiocarcinoma (TCGA, Firehose Legacy)

|Cholangiocarcinoma (TCGA. PanCancer Atlas) | Gallbladder Cancer (MSK. Cancer 2018)

| Gallbladder Carcinoma (Shanghai, Nat Genet 2014) 【Intrahepatic Cholangiocarcinoma (JHU, Nat Genet 2013)

IIntrahepatic Cholangiocarcinoma (Shanghai, Nat Commun 2014)

D

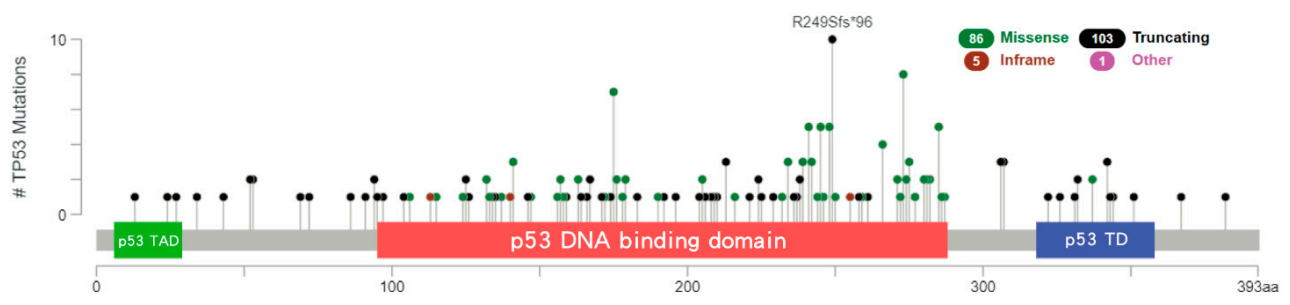

Figure 2. TP53 mutations in biliary tract cancers (BTCs). (A) Frequency of TP53 mutations in 
different studies. (B) The frequency of TP53 mutations in subtypes of BTC. (C) Collective results of available datasets of TP53 mutation in BTCs. (D) Lollipop plots for tumor TP53 mutations in BTC patients. TP53 mutations frequently occur in the DNA binding domain of p53 (red region). Black, green, pink and blue dots indicate truncating, missense, in-frame and other mutations, respectively. When different mutation types occur at a single position, the color of the circle indicates the most frequent mutation type. TAD, transactivation domain; TD, tetramerization domain. Data were accessed at cBioPortal on 3 September 2020. Please add explanation for ",$+-{ }^{\prime \prime}$ in image.

In addition to mutation, the function of 553 can be suppressed by MDM2 amplification, or induced MDM2 activity due to loss of its negative regulator, p14ARF, as a result of deletion of the CKDN2A locus. Therefore, not only p53 but also the integrity of the CKDN2A(p14ARF)/MDM2/p53 axis may play an important role in BTC (Figure 3). Alterations of MDM2 (mostly amplification) and CKDN2A (mostly deep deletion) occur in $4 \%$ and $10 \%$ of BTCs, respectively (Figure 3A). Furthermore, TP53 mutation and MDM2 alteration are mutually exclusive $(p=0.011)$ in BTCs, implying either gene alteration may be sufficient to abrogate $\mathrm{p} 53$ function leading to tumorigenesis (Figure $3 \mathrm{~B}$ ).

A

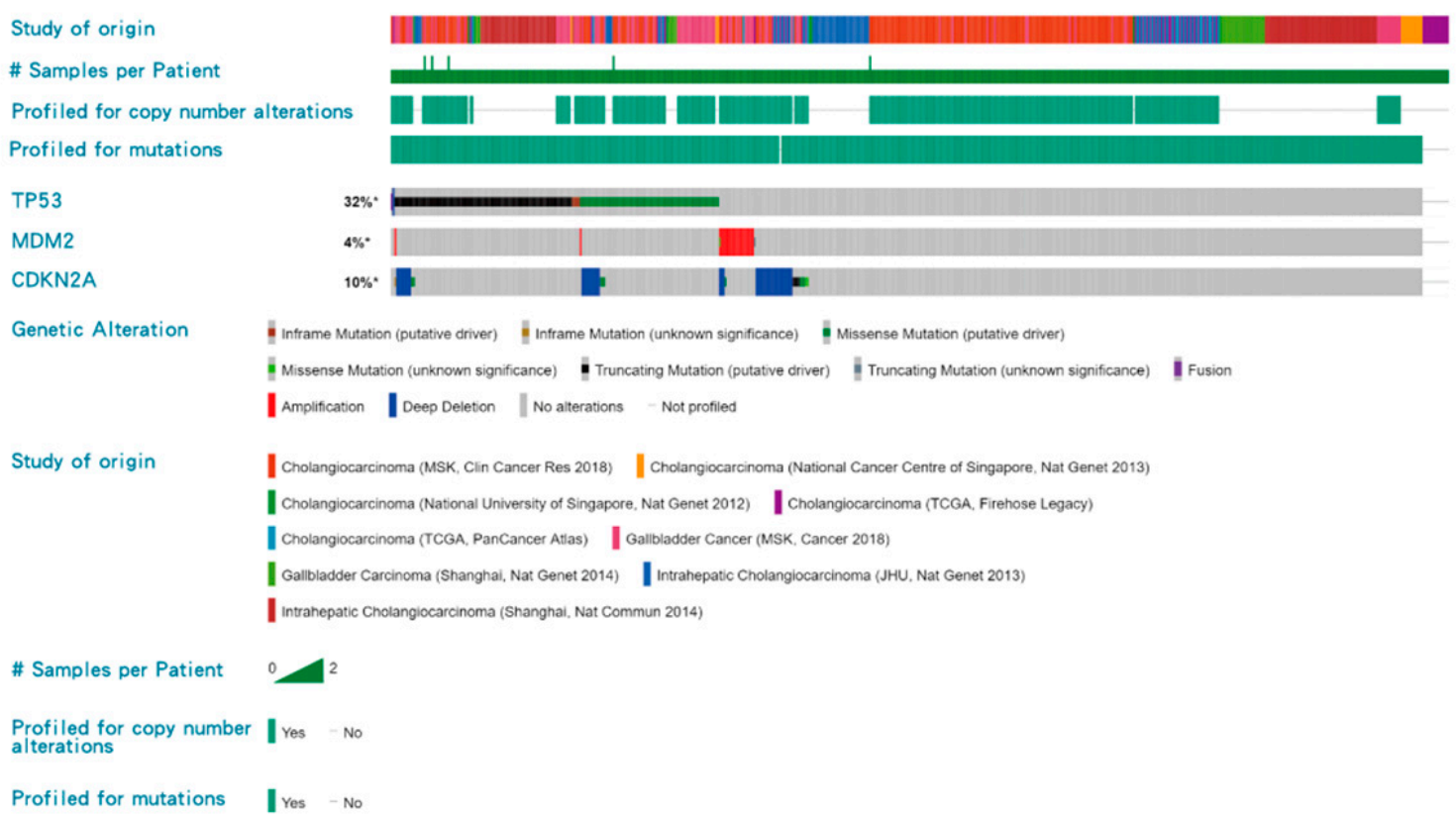

B

\begin{tabular}{|l|l|l|l|l|l|l|l|l|l|}
\hline A & B & Neither & A Not B & B Not A & Both & Log2 Odds Ratio & p-Value & $q$-Value & Tendency \\
\hline TP53 & MDM2 & 365 & 180 & 20 & 2 & -2.302 & 0.011 & 0.034 & Mutual exclusivity \\
\hline
\end{tabular}

Figure 3. TP53/MDM2/CDKN2A alterations in biliary tract cancers (BTCs). (A) Frequency of TP53/ MDM2/CDKN2A alterations in different studies. (B) The association between TP53/MDM2/CDKN2A alterations. Data were accessed at cBioPortal on 3 September 2020. 


\section{2. $p 53$ in Tumorigenesis of BTCs}

Unlike other cancers, the specific role of TP53 mutation in BTC tumorigenesis has not yet been well established, possibly due to the relative rarity compared with other cancers. Importantly, liver fluke- and/or viral hepatitis-positive BTCs have a higher incidence of TP53 mutations, reflecting distinct genetic alterations associated with different aetiologies [55-57]. Therefore, to better understand the tumorigenesis of BTC, comprehensive genome sequencing is needed for BTC patients from different environments associated with different pathological factors.

\section{3. $p 53$ as a Prognostic Factor in BTCs}

Early studies investigated the prognostic role of 553 protein expression by immunohistochemistry (IHC) and/or TP53 mutation in BTCs and the results are conflicting [58]. Some studies showed no association with survival and some showed p53 protein expression or TP53 mutation negatively impact survival [58]. However, one study showed p53 protein expression was associated with better survival [59]. It should be cautioned that the relationship between protein detection by IHC and p53 mutational status is complex. Some p53 mutant proteins resulting from point missense mutations are more stable than $\mathrm{p} 53^{\mathrm{WT}}$ when they result in conformational alteration, which leads to less transactivated MDM2 and also less affinity with MDM2. Such p53 mutants can be detected by strong IHC staining for p53. However, the p53 mutants resulting from nonsense mutations or frameshift insertions/deletions may not be detected if the p53 was simply examined by IHC. Therefore, gene sequencing is a more reliable method to indicate the potential loss of normal p53 function and, in some cases, dominant abnormal gain of function.

With the advent of next generation sequencing (NGS), comprehensive genetic profiling of BTCs has been investigated by different study groups. Based on the pooled data, patients with BTCs harboring TP53 mutation have a poorer survival outcome than patients with TP53 WT BTCs (Figure 4A,B). In addition, the combination of CDKN2A/MDM2/TP53 alterations indicating loss of p53 function provide a more comprehensive prediction of poor prognosis in patients with BTCs (Figure 4C,D). Due to the heterogeneity of patient characteristics and treatment in collected studies, sufficiently powered studies with more uniformly defined cohorts of patients are needed in the future to validate this finding.

\subsection{MDM2 as a Prognostic Factor in BTCs}

MDM2 is a negative regulator of p53 and is also transcriptionally transactivated and tightly regulated by $\mathrm{p} 53$. Therefore, MDM2 is expected to be overexpressed only in $\mathrm{p} 53^{\mathrm{WT}}$ tumors and MDM2 overexpression may be an alternative mechanism to suppress the function of $\mathrm{p} 53^{\mathrm{WT}}$, potentially resulting in aggressive tumor behaviors. An early report of 47 iCCA patients showed that MDM2 overexpression correlated with the Ki-67 labeling index $(p<0.03)$, presence of metastases $(p<0.01)$ and advanced tumor stage $(p<0.05)$ [60]. Another study enrolled 128 CCA patients in Thailand and evaluated the clinical significance of CD44 and MDM2. This study demonstrated that expression of CD44 and MDM2 in CCA correlated with poor clinicopathologic characteristics (high grade, large size, regional and distant metastases) and poor survival [61]. CD44 expression was associated with TP53 mutation and tumor stemness [62] and MDM2 expression could be taken to indicate tumors harboring $\mathrm{p} 53^{\mathrm{WT}}$, which is nevertheless being suppressed by MDM2. Therefore, both biomarkers may possibly reflect the nature of loss-of-function of $\mathrm{p} 53^{\mathrm{WT}}$, which is compatible with previous studies about the significance of TP53 mutation status in BTCs. However, this study did not analyze TP53 mutation, so that the real relationship between CD44/MDM2/TP53 was unknown, particularly for the tumors with CD44/MDM2 co-expression. 


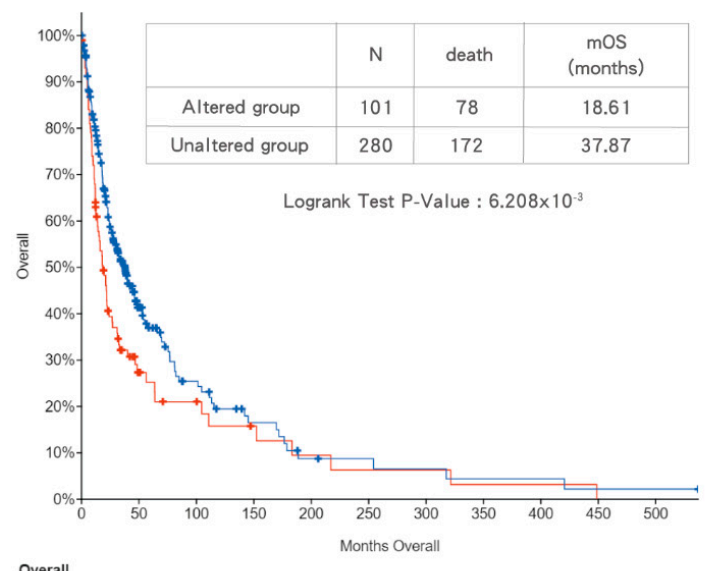

TP53 alterations

TP53 wild-type

C

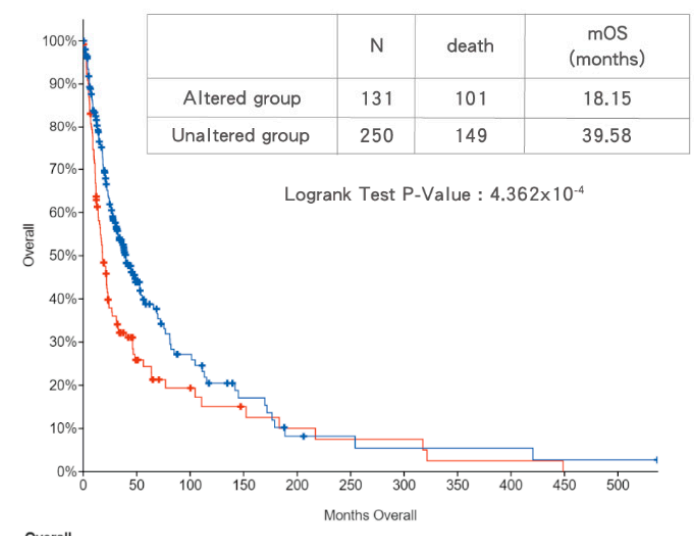

CDKN2A/MDM2/TP53 alterations CDKN2A/MDM2/TP53 wild-type
B

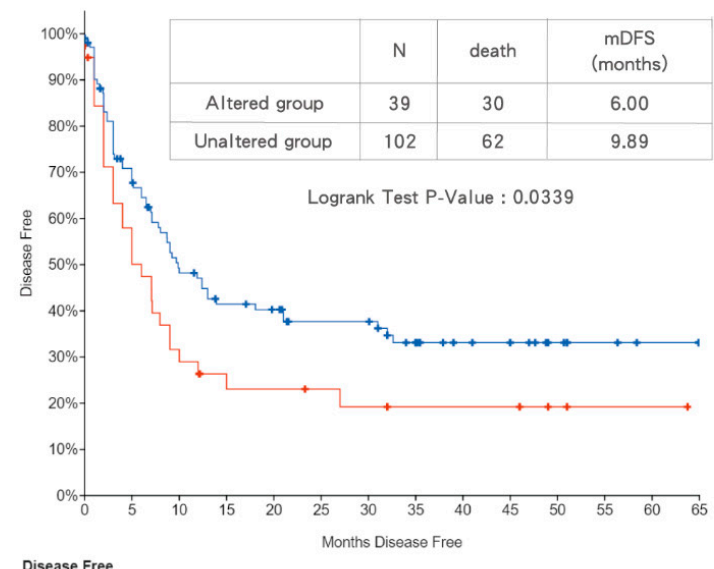

TP53 alterations

TP53 wild-type
D

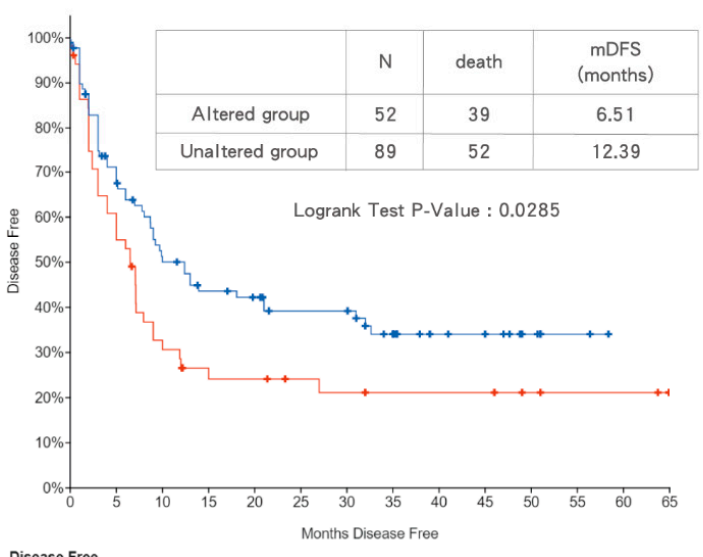

CDKN2A/MDM2/TP53 alterations CDKN2A/MDM2/TP53 wild-type

Figure 4. The impact of TP53 mutation (A,B) and CDKN2A/MDM2/TP53 alterations (C,D) on overall survival (OS) (A,C) and disease-free survival (DFS) (B,D) in biliary tract cancers (BTCs). Data were accessed at cBioPortal on 3 September 2020.

\section{4. p53 Plays a Role in Gemcitabine Resistance in Cancers}

Gemcitabine treatment induces a cellular DNA damage response (DDR) signaling cascade involving activation by phosphorylation of ataxia telangiectasia mutated (ATM), ataxia telangiectasia related (ATR) and p53. Once $\mathrm{p} 53^{\mathrm{WT}}$ is activated by phosphorylation and subsequent accumulation, it induces cell cycle arrest, allowing and facilitating DNA repair, or, depending on the cell type and level of damage, it triggers cell death (by apoptosis or alternative mechanisms) or cell senescence. However, in p53 ${ }^{\mathrm{MUT}}$ cancer, p53 loses its WT function and in some cases may gain MUT function, either way this allows survival rather than growth inhibition, but the lack of cell cycle arrest also results in replication of DNA on a damaged template and hence further mutations. In some cases of $\mathrm{p} 53^{\mathrm{WT}}$ cancer, WT $\mathrm{p} 53$ is suppressed by its negative regulators such as MDM2 and wild-type p53-induced phosphatase 1 (WIP1) (PPM1D). Either $\mathrm{p} 53^{\mathrm{MUT}}$ or $\mathrm{p} 53^{\mathrm{WT}}$ suppression by MDM2 is proposed to increase gemcitabine resistance (Figure 5) [63]. 


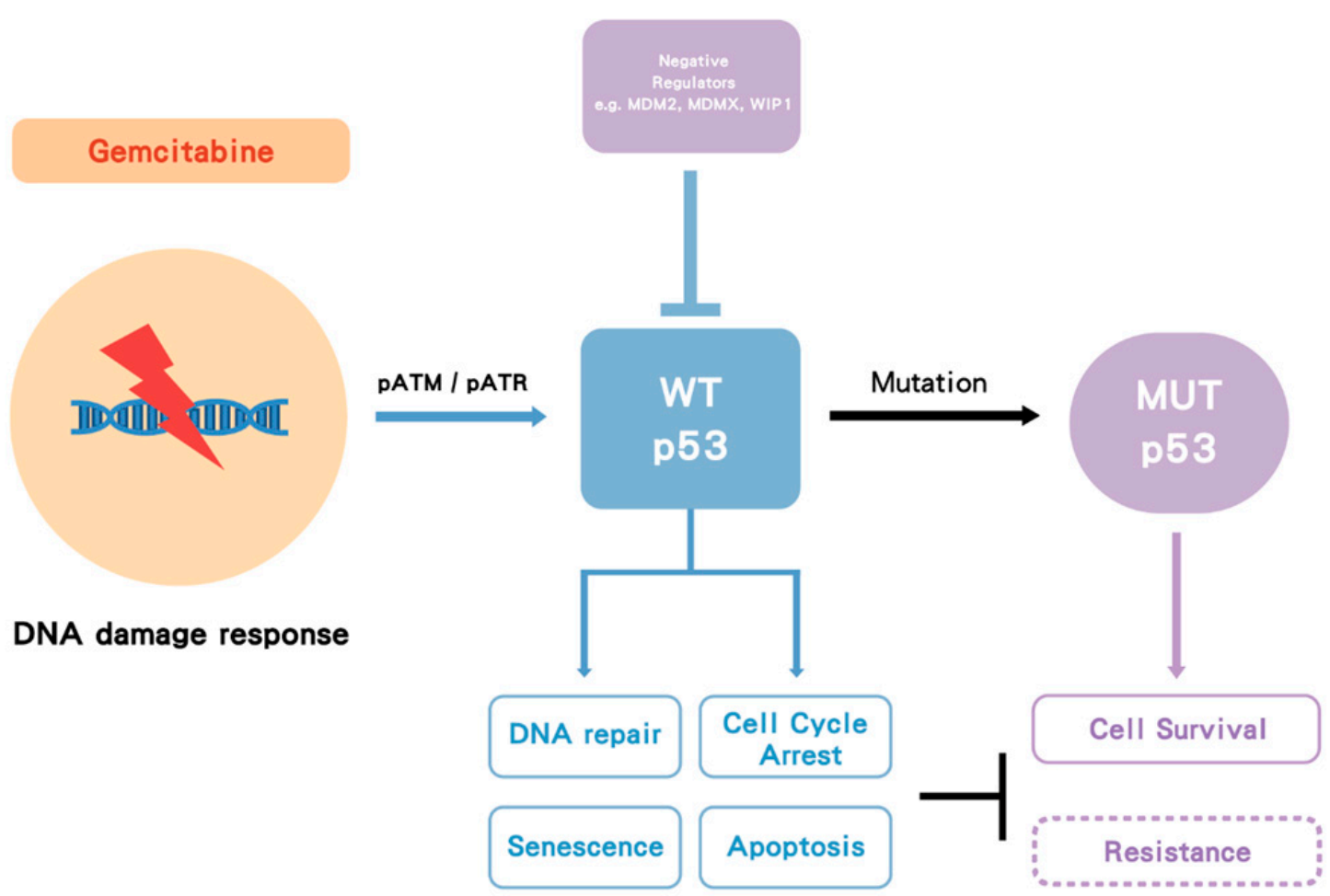

Figure 5. The proposed model of p53 impact on gemcitabine treatment. Gemcitabine induces a DNA damage response followed by activation of pATM/pATR and p53. Wild-type (WT) p53 activation can facilitate DNA repair, cell cycle arrest, apoptosis and senescence. Once p53 becomes mutated (MUT), it loses its WT function, and some mutant forms may gain function, which increases cell survival. In some cases, WT p53 is suppressed by its negative regulators such as MDM2/MDMX. Either p53 mutation or suppression by MDM2 may increase gemcitabine resistance. Dashed box indicates hypothesis.

However, studies regarding the role of p53 in gemcitabine resistance in BTCs are limited. As both pancreatic cancer and BTC have close anatomic location and similar histologic features, both were considered together in early studies. Palliative chemotherapy was demonstrated to improve both survival and quality of life for patients with advanced pancreatic cancer or BTC [64]. Gemcitabine became the standard treatment for both pancreatic cancer [65] and BTC [7]; therefore, studies related to gemcitabine resistance in pancreatic cancer may be applicable to BTCs and hence are discussed here.

Fiorini et al. demonstrated that $\mathrm{p} 53^{\mathrm{MUT}}$ enhanced gemcitabine resistance in pancreatic cancer. Gemcitabine stabilized both nuclear $\mathrm{p} 53^{\mathrm{WT}}$ and $\mathrm{p} 53^{\mathrm{MUT}}$ and only the latter (p53 ${ }^{\mathrm{MUT}}$ ) induced chemoresistance and hyperproliferation evidenced by siRNA-mediated knockdown induced chemosensitivity and apoptosis in p53 $3^{\mathrm{MUT}}$ but not in $\mathrm{p} 53^{\mathrm{WT}}$ cell lines. This may be associated with overexpression of $\mathrm{p} 53^{\mathrm{MUT}}$-dependent $C d k 1$ and CCNB1 genes. However, a synergistic effect of the combination with gemcitabine and "p53-reactivating" compounds (CP-31398 and RITA) was found in both p53 ${ }^{\mathrm{WT}}$ and $\mathrm{p} 53^{\mathrm{MUT}}$ pancreatic cancer cell lines, which may have been due to a mechanism that did not involve p53 [66]. In a mouse model of pancreatic cancer, Wornann et al. reported that loss of $\mathrm{p} 53^{\mathrm{WT}}$ function increased resistance to gemcitabine via activation of the JAK2-STAT3 pathway [67]. In a study by Dhyat et al. (2016) microRNA (miR) profiling in gemcitabine-resistant p53 $^{\text {MUT }}$ pancreatic cancer cell lines suggested the involvement of miRs in pathways controlling cell cycle, proliferation, and apoptosis. In-silico analysis in this study indicated that some of the dysregulated miRs were regulated by $\mathrm{p}^{\mathrm{MUT}}$. In addition, MRP-1, Bcl-2 and CDK-1 were predicted to be targets of the dysregulated miRs and significant overexpression of MRP-1 and Bcl-2 was seen in the resistant cell clones [68]. These observations suggest that $\mathrm{p} 53^{\mathrm{MUT}}$ may enhance chemoresistance via the dysregulation of miRs and that this might be associated with MRP-1 and Bcl-2 overexpression in $\mathrm{p} 53^{\mathrm{MUT}}$ pancreatic cancer.

In the clinical setting, a phase III study (CONKO-001) evaluated the efficacy of adjuvant gemcitabine in resected pancreatic cancer. Next generation DNA sequencing was performed in this trial to identify clinically relevant prognostic and predictive mutations. In untreated patients, TP53 mutation was a negative prognostic 
factor for disease-free survival (DFS) (HR: 2.434, $p=0.005$ ). Interestingly, however, TP53 mutation was a positive predictive factor for better DFS (HR: 0.235; $p<0.001$ in p53 ${ }^{\mathrm{MUT}}$; HR: $0.794, p=0.483$ in p53 ${ }^{\mathrm{WT}}$ ) with gemcitabine treatment, with a significant test for interaction of the treatment status with TP53 mutational status $(p=0.003)$ [69]. Only subsets of patients with available samples were retrospectively analyzed, limiting the significance of this study, but the findings provide evidence for the role of $\mathrm{p} 53^{\mathrm{MUT}}$ in pancreatic cancer, which may be relevant to BTC.

Further studies specific to BTC regarding p53 and chemoresistance are warranted to provide additional evidence, which would guide treatment. However, the above studies suggest a novel therapeutic strategy targeting both wild-type and mutant p53 tumors in combination with gemcitabine for pancreatic cancer as well as BTCs.

\section{Targeting p53 as a Therapeutic Strategy}

To overcome the $\mathrm{p} 53$-associated chemoresistance, $\mathrm{p} 53^{\mathrm{WT}}$ and $\mathrm{p} 53^{\mathrm{MUT}}$ situations should be considered individually as they may involve different chemoresistance mechanisms (Figure 6).

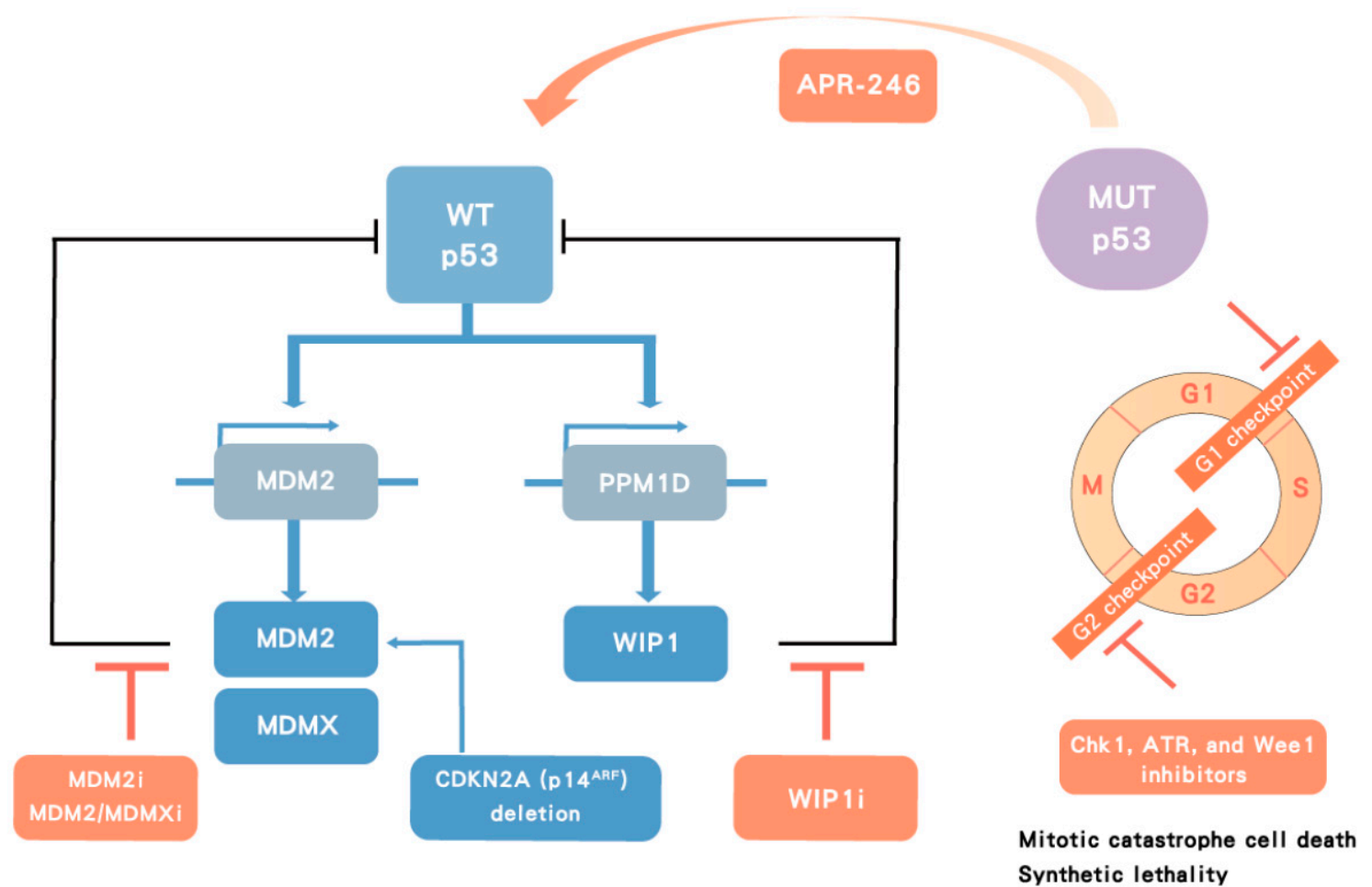

Figure 6. Therapeutic strategy targeting p53. In p53 wild-type (WT) cancers, p53 transactivates its negative regulators, MDM2 and wild-type p53-induced phosphatase 1 (WIP1), which in turn inhibit p53 function. MDMX cooperates with MDM2 to degrade p53. MDM2 inhibitors (MDM2i), dual MDM2/MDMX inhibitors (MDM2/MDMXi) and WIP1 inhibitors (WIP1i) target negative regulators of p53 leading to 553 stabilization and activation. In contrast, p53 mutant (MUT) tumors can potentially be treated with a direct activator, such as APR-246, or indirectly with Chk1, ataxia telangiectasia related (ATR), and Wee1 inhibitors, which lead to cell death by mitotic catastrophe in MUT p53 cancers.

\subsection{Targeting Mutant p53}

\subsubsection{Direct Targeting of Mutant p53}

Unlike most targeted therapy against oncoproteins resulting from oncogene alterations, targeting mutant p53 has been a challenge because $\mathrm{p} 53$ behaves as a tumor suppressor protein, where loss of function is the predominant mechanism, but also a subset of mutations result in dominant negative oncogenic behavior. Therefore, ideally not only inhibiting $\mathrm{p} 53^{\mathrm{MUT}}$ gain of function mutation but also activating $\mathrm{p} 53^{\mathrm{WT}}$ function is necessary for BTCs. If only p53 $3^{\mathrm{MUT}}$ is suppressed by targeted therapy, the $\mathrm{p} 53^{\mathrm{WT}}$ may also need to be activated to maximize the efficacy of p53-targeted therapy. In addition, although the p53 mutations are frequently found in exons four to nine, which encode the DNA-binding domain of p53, no unique hotspots are available for targeting in all cases. APR-246, a 
PRIMA-1 analog, has been developed to covalently bind to cysteines of the core domain and modify the core domain of $\mathrm{p} 53^{\mathrm{MUT}}$ to restore both the WT conformation and function via conversion to the reactive electrophile methylene quinuclidinone, in order to reconstitute endogenous $\mathrm{p} 53^{\mathrm{WT}}$ activity, in principle leading to cell cycle arrest and apoptosis of p53 $3^{\mathrm{MUT}}$ tumor cells (Figure 6) [70]. Although the mechanism and specificity of APR-246 for $\mathrm{p} 53^{\mathrm{MUT}}$ tumor cells has been questioned, the FDA granted breakthrough therapy designation for APR-246 in combination with azacitidine for the treatment of patients with myelodysplastic syndromes (MDS) with a susceptible TP53 mutation based on a promising early phase II study (NCT03588078)[71]. A phase III study is ongoing to compare the rate of complete remission and duration of complete remission in patients with p53 $3^{\mathrm{MUT}}$ MDS receiving APR-246 and azacitidine or azacitidine alone (NCT03745716). As the results in MDS have been taken to support the concept of reactivating susceptible forms of $5^{\mathrm{MUT}}$, clinical trials regarding APR-246 alone or in combination with chemotherapy are ongoing in a range of hematologic and solid malignancies.

Preclinical and clinical studies of p53 activators including APR-246 are being widely investigated. APR-246 has been reported to overcome chemoresistance to cisplatin and doxorubicin and to synergize with gemcitabine in p53 ${ }^{\mathrm{MUT}}$ ovarian cancer cells [72]. Furthermore, combination of APR-246 with dexamethasone or doxorubicin was reported to show synergistic effects in multiple myeloma cell lines and primary multiple myeloma samples [73]. The efficacy and safety of such strategies targeting p53 ${ }^{\mathrm{MUT}}$ should be confirmed in clinical trials and may be applicable for BTC treatment in the future (NCT04383938).

\subsubsection{Indirect Targeting of Mutant p53 by Synthetic Lethality}

Another possible therapeutic option is to target cell cycle regulators in $\mathrm{p}^{\mathrm{MUT}}$ cancer as a potential synthetic lethality strategy to kill p53 ${ }^{\mathrm{MUT}}$ cancer cells selectively. It has been hypothesized that cancer cells deficient in p53 function, due to p53 mutations or other defects in the p53 signaling pathway, lack a G1 cell cycle checkpoint and therefore may depend more on the G2 checkpoint for cell survival [74-76]. Abrogation of the G2 checkpoint by inhibitors of Chk1 [74], Wee1 [77], or ATR [78] may therefore selectively sensitize p53 defective cancer cells to DNA damaging agents resulting in cell death by mitotic catastrophe [79], while relatively sparing the surrounding normal p53-proficient cells. In addition, Chk1, ATR, and Wee1 inhibitor treatment has been reported to result in DNA damage in S phase, which may contribute to the cytotoxic effects of these inhibitors (Figure 6) $[80,81]$. Taking in vitro studies of lung cancer for example, the Chk1 inhibitor UCN-01 [82], Wee1 inhibitor AZD1775 [83], ATR inhibitor VX-970 [84] in combination with cytotoxic agents (irradiation or cisplatin) have been shown to selectively target p53-deficient lung cancer cells, demonstrated using otherwise isogenic p53 ${ }^{\mathrm{MUT}}$ and p53 ${ }^{\mathrm{WT}}$ paired cell systems.

Adavosertib (AZD1775), a Wee1 inhibitor, is currently being investigated in clinical trials. In preclinical studies, AZD1775 was reported to selectively radiosensitize $\mathrm{p} 53^{\mathrm{MUT}}$ but not in $\mathrm{p} 53^{\mathrm{WT}}$ cell lines [85]. In contrast, another study demonstrated AZD1775-mediated potentiation of antimetabolite chemotherapeutics independent of TP53 status in both hematologic and solid tumor models [86]. Therefore, p53 dependence may be restricted to certain cancers and/or treatment modalities. Biomarker analysis in a phase one study of AZD1775 showed response rates of $21 \%$ and $12 \%$ for $T P 53^{\mathrm{MUT}}$ and $T P 53^{\mathrm{WT}}$ tumors, respectively, indicating a degree of selection for TP53 ${ }^{\mathrm{MUT}}$ cancers [87]. Phase II studies of AZD1775 alone and in combination with other cytotoxic agents are ongoing and larger cohort studies are needed to confirm whether p53 mutation is a predictive factor for use of AZD1775. Several clinical trials of AZD1775 are ongoing in various cancers (NCT01748825, NCT04462952, NCT02482311).

AZD6738, an ATR inhibitor, has shown preclinical activity in panels of BTC cell lines, particularly with SNU478 and SNU869 cell lines (both p53 ${ }^{\text {MUT }}$ ) [88]. The combination of AZD6738 and MK1775 has also been reported to have synergistic effects in p53 ${ }^{\mathrm{MUT}}$ BTC cell lines [89]. Early phase studies of AZD6738 are ongoing in various cancers [90] and also AZD6738 in combination with durvalumab in BTCs (NCT04298008).

Therefore, targeting cell cycle checkpoints to induce mitotic catastrophe cell death in p53 ${ }^{\mathrm{MUT}}$ cancers is an emerging strategy that is being explored in the clinical setting.

\subsection{Targeting Wild-Type p53}

In $\mathrm{p} 53^{\mathrm{WT}}$ cancers, the $\mathrm{p} 53$ function is held back by its negative regulators. Therefore, inhibition of negative regulators to activate $\mathrm{p} 53$ function should be investigated in $\mathrm{p} 53^{\mathrm{WT}}$ cancers. 


\subsubsection{Targeting MDM2, an E3 Ligase and Negative Regulator of p53}

MDM2, a transcriptional target of p53, is the most important negative regulator of p53. It binds to p53 and blocks its transcriptional activity, as well as targeting p53 for degradation by ubiquitination, thus inhibiting and controlling the growth inhibitory and pro-apoptotic activity of p53. Hence, MDM2 can limit the effectiveness of p53 and p53-dependent therapies, and thus promote the development and survival of cancer cells [50]. The essential role of MDM2 in the negative regulation of p53 was highlighted in early studies, which showed that germline gene knockout of MDM2 in mice was embryonically lethal, but could be rescued by co-deletion of the mouse gene encoding p53 [47]. The MDM2-p53 binding antagonists were developed to bind to MDM2 in the p53-binding pocket, allow p53 to accumulate, and then activate the p53 pathway in cancer cells, resulting in cell cycle arrest and apoptosis or senescence, depending on the cell type. This was first demonstrated with Nutlin-3, which was shown to inhibit proliferation and induce cell death for human cancer cell lines in vitro and for tumor xenografts in nude mice [91]. Subsequently, a number of MDM2 antagonists (RG7388 (Idasanutlin), HDM201, AMG232, etc.) have been developed and studied preclinically in vitro and in vivo. A number of these agents have gone on to be investigated in clinical trials (NCT02143635, NCT03362723).

Current investigations of MDM2 inhibitors are exploring their use in combination treatments with cytotoxic agents or targeted therapy [63]. The combination of MDM2 inhibitors and gemcitabine has been studied in p53 ${ }^{\mathrm{WT}}$ mantle cell lymphoma using MI-63 and MI-219 in vitro and in vivo. This combination treatment also demonstrated promising results for primary patient samples ex vivo [92].

\subsubsection{Targeting MDM2/MDMX}

MDMX is a paralogue of MDM2 and has been reported to augment MDM2 activity and contribute to p53 degradation [93]. Compared with MDM2/p53 antagonists, the agents designed to target MDMX/p53 are relatively limited and, despite extensive efforts, small molecule inhibitors specific for MDMX have yet to be developed, although there are some compounds that inhibit both MDM2 and MDMX. For example, RO5963 has been demonstrated to inhibit p53 binding to MDM2/MDMX, and MDMX overexpression was associated with an apoptotic response to RO5963 treatment [94]. Preclinical studies have reported the activity of dual MDM2/MDMX inhibitors $[95,96]$ and currently the ALRN-6924 peptide, alone or in combination with cytotoxic agents, is being investigated in early phase clinical trials (NCT03654716, NCT03725436).

\subsubsection{Targeting WIP1, a Phosphatase of p53}

The PPM1D gene that encodes wild-type p53-induced phosphatase 1 (WIP1) is another important homeostatic negative regulator of p53 function and stability, by both directly and indirectly controlling the phosphorylation status of p53 after cellular stress. The PPM1D gene is also a direct transcriptional target of p53, thus forming a negative auto-regulatory loop with the p53 network by dephosphorylating p53 (Ser15) and other DDR signaling components (such as ATM, ATR, and MDM2) involved in p53 post-translational regulation [97].

GSK2830371 is a small molecule allosteric inhibitor, which has been selected to block the enzymatic activity of WIP1. It binds to a flap subdomain of WIP1 and also enhances ubiquitin-mediated degradation of WIP1 [98]. Pre-clinical studies have shown that GSK2830371 can enhance p53-mediated tumor suppression by MDM2 inhibitors [99,100] or by chemotherapy [101]. Although GSK2830371 is a useful tool compound for exploratory proof of concept studies, this compound does not have in vivo properties suitable for clinical development and the lack of suitable WIP1 inhibitors currently precludes investigation of this target in clinical trials [102].

\section{Conclusions}

TP53 mutation is associated with adverse clinicopathological characteristics and poor survival of BTC patients. Preclinical studies have demonstrated that p53 mutation enhances gemcitabine resistance; therefore, targeting mutant p53 may be a novel therapeutic strategy for treatment of BTCs. Directly targeting mutant p53 by p53 activators or indirectly targeting cell cycle checkpoints to exploit potential synthetic lethality are strategies to explore for gemcitabine-resistant $\mathrm{p} 53^{\mathrm{MUT}}$ BTCs. In contrast, for the majority of TP53 ${ }^{\mathrm{WT}}$ tumor cases, activation of p53 by inhibition of its negative regulators (MDM2 and WIP1) is an option worthy of investigation.

In the future, combination therapies consisting of cytotoxic drugs with established activity in BTC and novel small molecules targeting p53 may be the key to more effective treatment of these cancers (Table 1). Overcoming resistance to traditional anticancer drugs, including gemcitabine, by development of synergistic combinations 
with novel targeted small molecules has the potential to improve the activities and outcomes of chemotherapy in BTC.

Table 1. Selected clinical trials targeting the p53 pathway in solid cancers.

\begin{tabular}{ccccc}
\hline Class & Drugs & Phase & Tumor Types & ClinicalTrials.gov \\
\hline p53 activator & APR-246 + Pembrolizumab & $1 / 2$ & Solid Cancers & NCT04383938 \\
\hline \multirow{2}{*}{ Wee1 inhibitor } & AZD1775 & 1 & Solid Cancers & $\begin{array}{c}\text { NCT01748825 } \\
\text { NCT04462952 } \\
\end{array}$ \\
\hline ATR inhibitor & AZD6738 + Durvalumab & 2 & Bile Duct Cancer & NCT04298008 \\
\hline \multirow{2}{*}{ MDM2 inhibitor } & HDM201 & 1 & WT-p53 Solid Cancers & NCT02143635 \\
\cline { 2 - 5 } & Idasanutlin & 1 & Solid Cancers & NCT03362723 \\
\hline $\begin{array}{c}\text { MDM2/MDMX } \\
\text { Inhibitor }\end{array}$ & ALRN-6924 + Paclitaxel & 1 & WT-p53 Solid Cancers & NCT03725436 \\
\cline { 2 - 5 } & ALRN-6924 & 1 & WT-p53 Pediatric Cancer & NCT03654716 \\
\hline
\end{tabular}

Author Contributions: Conceptualization, C.-E.W. and C.-N.Y.; writing, review and editing, C.-E.W., Y.-R.P., C.-N.Y. and J.L.; resources and discussion, C.-E.W. and J.L.; funding acquisition, C.-E.W. and C.-N.Y. All authors have read and agreed to the published version of the manuscript.

Funding: This work was founded by grants from Linkou Chang-Gung Memorial Hospital (NMRPG3K6201, CMRPG3K0601, CMRPG3J0971 2 and CRRPG3K0021 to CEW, CMRPG3I0241 2, CORPG3J0251 2, CRRPG3K0011, CRRPG3K0031 and CMRPG3K0711 to CNY) and the Ministry of Science and Technology (109-2314-B-182A-148 -MY3 to CEW). The APC was funded by Linkou Chang-Gung Memorial Hospital.

Acknowledgments: This work was supported by grants from Linkou Chang-Gung Memorial Hospital. Please refer to funding section.

Conflicts of Interest: The authors have no conflicts of interest to disclose.

\section{References}

1. Ustundag, Y.; Bayraktar, Y. Cholangiocarcinoma: A compact review of the literature. World J. Gastroenterol. 2008, 14, 6458-6466. [CrossRef]

2. Khan, S.A. Cholangiocarcinoma. Lancet 2005, 366, 1303-1314. [CrossRef]

3. Patel, T. Increasing incidence and mortality of primary intrahepatic cholangiocarcinoma in the United States. Hepatology 2001, 33, 1353-1357. [CrossRef]

4. Wu, C.E.; Chen, M.H.; Yeh, C.N. mTOR Inhibitors in Advanced Biliary Tract Cancers. Int. J. Mol. Sci. 2019, 20, 500. [CrossRef]

5. Shaib, Y.; El-Serag, H.B. The epidemiology of cholangiocarcinoma. Semin. Liver Dis. 2004, 24, 115-125. [CrossRef]

6. $\mathrm{Wu}, \mathrm{C} . \mathrm{E}$. Prognostic and predictive factors for Taiwanese patients with advanced biliary tract cancer undergoing frontline chemotherapy with gemcitabine and cisplatin: A real-world experience. BMC Cancer 2020, 20, 422. [CrossRef]

7. Valle, J. Cisplatin plus gemcitabine versus gemcitabine for biliary tract cancer. N. Engl. J. Med. 2010, 362, 1273-1281. [CrossRef]

8. Hezel, A.F.; Deshpande, V.; Zhu, A.X. Genetics of Biliary Tract Cancers and Emerging Targeted Therapies. J. Clin. Oncol. 2010, 28, 3531-3540. [CrossRef]

9. Zhu, A.X.; Hezel, A.F. Development of Molecularly Targeted Therapies in Biliary Tract Cancers: Reassessing the Challenges and Opportunities. Hepatology 2011, 53, 695-704. [CrossRef]

10. Sahu, S.; Sun, W. Targeted therapy in biliary tract cancers-current limitations and potentials in the future. J. Gastrointest. Oncol. 2017, 8, 324-336. [CrossRef]

11. Lee, J. Gemcitabine and oxaliplatin with or without erlotinib in advanced biliary-tract cancer: A multicentre, open-label, randomised, phase 3 study. Lancet Oncol. 2012, 13, 181-188. [CrossRef]

12. Malka, D. Gemcitabine and oxaliplatin with or without cetuximab in advanced biliary-tract cancer (BINGO): A randomised, open-label, non-comparative phase 2 trial. Lancet Oncol. 2014, 15, 819-828. [CrossRef] 
13. Valle, J.W. Cediranib or placebo in combination with cisplatin and gemcitabine chemotherapy for patients with advanced biliary tract cancer (ABC-03): A randomised phase 2 trial. Lancet Oncol. 2015, 16,967-978. [CrossRef]

14. Chen, J.S. A KRAS mutation status-stratified randomized phase II trial of gemcitabine and oxaliplatin alone or in combination with cetuximab in advanced biliary tract cancer. Ann. Oncol. 2015, 26, 943-949. [CrossRef] [PubMed]

15. Leone, F. Panitumumab in combination with gemcitabine and oxaliplatin does not prolong survival in wild-type KRAS advanced biliary tract cancer: A randomized phase 2 trial (Vecti-BIL study). Cancer 2016, 122, 574-581. [CrossRef]

16. Filippi, R. Pharmacotherapeutic options for biliary tract cancer: Current standard of care and new perspectives. Expert Opin. Pharmacother. 2019, 20, 2121-2137. [CrossRef]

17. Wu, C.E. Chemotherapy with gemcitabine plus cisplatin in patients with advanced biliary tract carcinoma at Chang Gung Memorial Hospital: A retrospective analysis. Chang. Gung Med. J. 2012, 35, 420-427.

18. Farshidfar, F. Integrative Genomic Analysis of Cholangiocarcinoma Identifies Distinct IDH-Mutant Molecular Profiles. Cell Rep. 2017, 19, 2878-2880. [CrossRef]

19. Mahipal, A. FGFR2 genomic aberrations: Achilles heel in the management of advanced cholangiocarcinoma. Cancer Treat. Rev. 2019, 78, 1-7. [CrossRef]

20. Abou-Alfa, G.K. Pemigatinib for previously treated, locally advanced or metastatic cholangiocarcinoma: A multicentre, open-label, phase 2 study. Lancet Oncol. 2020, 21, 671-684. [CrossRef]

21. Piha-Paul, S.A.; Oh, D.; Ueno, M.; Malka, D.; Chung, H.C.; Nagrial, A.; Kelley, R.K.; Ros, W.; Italiano, A.; Nakagawa, K.; et al. Efficacy and safety of pembrolizumab for the treatment of advanced biliary cancer: Results from the KEYNOTE-158 and KEYNOTE-028 studies. Int. J. Cancer 2020, 147, 2190-2198. [CrossRef] [PubMed]

22. Goldstein, D.; Lemech, C.; Valle, J. New molecular and immunotherapeutic approaches in biliary cancer. ESMO Open 2017, 2 (Suppl. S1), e000152. [CrossRef] [PubMed]

23. Le, D.T.; Durham, J.N.; Smith, K.N.; Wang, H.; Bartlett, B.R.; Aulakh, L.K.; Lu, S.; Kemberling, H.; Wilt, C.; Luber, B.S.; et al. Mismatch repair deficiency predicts response of solid tumors to PD-1 blockade. Science 2017, 357, 409-413. [CrossRef] [PubMed]

24. Winkelmann, R.; Schneider, M.; Hartmann, S.; Schnitzbauer, A.A.; Zeuzem, S.; Peveling-Oberhag, J.; Hansmann, M.-L.; Walter, D. Microsatellite Instability Occurs Rarely in Patients with Cholangiocarcinoma: A Retrospective Study from a German Tertiary Care Hospital. Int. J. Mol. Sci. 2018, 19, 1421. [CrossRef] [PubMed]

25. Goeppert, B. Mismatch repair deficiency is a rare but putative therapeutically relevant finding in non-liver fluke associated cholangiocarcinoma. Br. J. Cancer 2019, 120, 109-114. [CrossRef]

26. Lane, D.; Crawford, L.V. T antigen is bound to a host protein in SV40-transformed cells. Nature 1979, 278, 261-263. [CrossRef]

27. Linzer, D.I.; Levine, A.J. Characterization of a $54 \mathrm{~K}$ dalton cellular SV40 tumor antigen present in SV40-transformed cells and uninfected embryonal carcinoma cells. Cell 1979, 17, 43-52. [CrossRef]

28. Kress, M.; May, E.; Cassingena, R.; May, P. Simian virus 40-transformed cells express new species of proteins precipitable by anti-simian virus 40 tumor serum. J. Virol. 1979, 31, 472-483. [CrossRef]

29. Melero, J.A.; Stitt, D.T.; Mangel, W.F.; Carroll, R.B. Identification of new polypeptide species (48-55K) immunoprecipitable by antiserum to purified large T antigen and present in SV40-infected and -transformed cells. Virology 1979, 93, 466-480. [CrossRef]

30. Smith, A.E.; Smith, R.; Paucha, E. Characterization of different tumor antigens present in cells transformed by simian virus 40. Cell 1979, 18, 335-346. [CrossRef]

31. Eliyahu, D. Participation of p53 cellular tumour antigen in transformation of normal embryonic cells. Nature 1984, 312, 646-649. [CrossRef] [PubMed]

32. Jenkins, J.R.; Rudge, K.; Currie, G.A. Cellular immortalization by a cDNA clone encoding the transformation-associated phosphoprotein p53. Nature 1984, 312, 651-654. [CrossRef] [PubMed]

33. Parada, L.F.; Land, H.; Weinberg, R.A. Cooperation between gene encoding p53 tumour antigen and ras in cellular transformation. Nature 1984, 312, 649-651. [CrossRef] [PubMed]

34. Eliyahu, D.; Goldfinger, N.; Pinhasi-Kimhi, O.; Shaulsky, G. Meth A fibrosarcoma cells express two transforming mutant p53 species. Oncogene 1988, 3, 313-321. 
35. Finlay, C.A.; Hinds, P.W.; Tan, T.H.; Eliyahu, D.; Oren, M. Activating mutations for transformation by p53 produce a gene product that forms an hsc70-p53 complex with an altered half-life. Mol. Cell. Biol. 1988, 8, 531-539. [CrossRef]

36. Baker, S.J.; Fearon, E.R.; Nigro, J.M.; Hamilton, S.R.; Preisinger, A.C. Chromosome 17 deletions and p53 gene mutations in colorectal carcinomas. Science 1989, 244, 217-221. [CrossRef]

37. Finlay, C.A.; Hinds, P.W.; Levine, A.J. The p53 proto-oncogene can act as a suppressor of transformation. Cell 1989, 57, 1083-1093. [CrossRef]

38. Malkin, D.; Li, F.P.; Strong, L.C.; Fraumeni Jr, J.F. Germ line p53 mutations in a familial syndrome of breast cancer, sarcomas, and other neoplasms. Science 1990, 250, 1233-1238. [CrossRef]

39. Fields, S.; Jang, S. Presence of a potent transcription activating sequence in the p53 protein. Science 1990, 249, 1046-1049. [CrossRef]

40. Bargonetti, J.; Friedman, P.N.; Kern, S.E.; Bert, V. Wild-type but not mutant p53 immunopurified proteins bind to sequences adjacent to the SV40 origin of replication. Cell 1991, 65, 1083-1091. [CrossRef]

41. El-Deiry, W.S.; Tokino, T.; Velculescu, V.E.; Levy, D.B. WAF1, a potential mediator of p53 tumor suppression. Cell 1993, 75, 817-825. [CrossRef]

42. Toshiyuki, M.; Reed, J.C. Tumor suppressor p53 is a direct transcriptional activator of the human bax gene. Cell 1995, 80, 293-299. [CrossRef]

43. Momand, J.; Zambetti, G.P.; Olson, D.C.; George, D. The mdm-2 oncogene product forms a complex with the p53 protein and inhibits p53-mediated transactivation. Cell 1992, 69, 1237-1245. [CrossRef]

44. Oliner, J.D.; Pietenpol, J.A.; Thiagalingam, S.; Gyuris, J. Oncoprotein Mdm2 Conceals the Activation Domain of Tumor Suppressor-P53. Nature 1993, 362, 857-860. [CrossRef]

45. Shvarts, A.; Steegenga, W.T.; Riteco, N.; Van Laar, T. MDMX: A novel p53-binding protein with some functional properties of MDM2. EMBO J. 1996, 15, 5349-5357. [CrossRef]

46. Linares, L.K.; Hengstermann, A. HdmX stimulates Hdm2-mediated ubiquitination and degradation of p53. Proc. Natl. Acad. Sci. USA 2003, 100, 12009-12014. [CrossRef]

47. Jones, S.N.; Roe, A.E.; Donehower, L.A.; Bradley, A. Rescue of Embryonic Lethality in Mdm2-Deficient Mice by Absence of P53. Nature 1995, 378, 206-208. [CrossRef]

48. Wade, M.; Wang, Y.V.; Wahl, G.M. The p53 orchestra: Mdm2 and Mdmx set the tone. Trends Cell Biol. 2010, 20, 299-309. [CrossRef]

49. Levine, A.J.; Momand, J.; Finlay, C.A. The p53 tumour suppressor gene. Nature 1991, 351, 453-456. [CrossRef]

50. Brown, C.J.; Lain, S.; Verma, C.S.; Fersht, A.R.; Lane, D.P. Awakening guardian angels: Drugging the p53 pathway. Nat. Rev. Cancer 2009, 9, 862-873. [CrossRef]

51. Olivier, M.; Hollstein, M.; Hainaut, P. TP53 mutations in human cancers: Origins, consequences, and clinical use. Cold Spring Harb. Perspect. Biol. 2010, 2, a001008. [CrossRef] [PubMed]

52. Hollstein, M.; Sidransky, D.; Vogelstein, B. p53 mutations in human cancers. Science 1991, 253, 49-53. [CrossRef] [PubMed]

53. Wade, M.; Li, Y.C.; Wahl, G.M. MDM2, MDMX and p53 in oncogenesis and cancer therapy. Nat. Rev. Cancer 2013, 13, 83-96. [CrossRef] [PubMed]

54. Muller, P.A.; Vousden, K.H. p53 mutations in cancer. Nat. Cell Biol. 2013, 15, 2-8. [CrossRef]

55. Chan-On, W.; Nairismägi, M.L.; Ong, C.K.; Lim, W.K.; Dima, S.; Pairojkul, C.; Lim, K.H.; McPherson, J.R.; Cutcutache, I.; Heng, H.L.; et al. Exome sequencing identifies distinct mutational patterns in liver fluke-related and non-infection-related bile duct cancers. Nat. Genet. 2013, 45, 1474-1478. [CrossRef]

56. Ong, C.K.; Subimerb, C.; Pairojkul, C.; Wongkham, S. Exome sequencing of liver fluke-associated cholangiocarcinoma. Nat. Genet. 2012, 44, 690-693. [CrossRef]

57. Zou, S.; Li, J.; Zhou, H.; Frech, C. Mutational landscape of intrahepatic cholangiocarcinoma. Nat. Commun. 2014, 5, 5696. [CrossRef]

58. Briggs, C.D.; Neal, C.P.; Mann, C.D.; Steward, W.P. Prognostic molecular markers in cholangiocarcinoma: A systematic review. Eur. J. Cancer 2009, 45, 33-47. [CrossRef]

59. Argani, P.; Shaukat, A.; Kaushal, M.; Wilentz, R.E. Differing rates of loss of DPC4 expression and of p53 overexpression among carcinomas of the proximal and distal bile ducts. Cancer 2001, 91, 1332-1341. [CrossRef] 
60. Horie, S.; Endo, K.; Kawasaki, H.; Terada, T. Overexpression of MDM2 protein in intrahepatic cholangiocarcinoma: Relationship with p53 overexpression, Ki-67 labeling, and clinicopathological features. Virchows Arch. 2000, 437, 25-30. [CrossRef]

61. Wattanawongdon, W.; Bartpho, T.S.; Tongtawee, T. Expression of CD44 and MDM2 in cholangiocarcinoma is correlated with poor clinicopathologic characteristics. Int. J. Clin. Exp. Pathol. 2019, 12, 3961-3967. [PubMed]

62. Solomon, H.; Dinowitz, N.; Pateras, I.S.; Cooks, T. Mutant p53 gain of function underlies high expression levels of colorectal cancer stem cells markers. Oncogene 2018, 37, 1669-1684. [CrossRef] [PubMed]

63. Kocik, J.; Machula, M.; Wisniewska, A.; Surmiak, E. Helping the Released Guardian: Drug Combinations for Supporting the Anticancer Activity of HDM2 (MDM2) Antagonists. Cancers 2019, 11, 1014. [CrossRef] [PubMed]

64. Glimelius, B.; Hoffman, B.K.; Sjödén, P.O.; Jacobsson, G. Chemotherapy improves survival and quality of life in advanced pancreatic and biliary cancer. Ann. Oncol. 1996, 7, 593-600. [CrossRef]

65. Burris, H.A., 3rd; Moore, M.J.; Andersen, J. Improvements in survival and clinical benefit with gemcitabine as first-line therapy for patients with advanced pancreas cancer: A randomized trial. J. Clin. Oncol. 1997, 15, 2403-2413. [CrossRef]

66. Fiorini, C.; Cordani, M.; Padroni, C.; Blandino, G. Mutant p53 stimulates chemoresistance of pancreatic adenocarcinoma cells to gemcitabine. Biochim. Biophys. Acta 2015, 1853, 89-100. [CrossRef]

67. Wormann, S.M.; Song, L.; Ai, J.; Diakopoulos, K.N. Loss of P53 Function Activates JAK2-STAT3 Signaling to Promote Pancreatic Tumor Growth, Stroma Modification, and Gemcitabine Resistance in Mice and Is Associated With Patient Survival. Gastroenterology 2016, 151, 180-193.e12. [CrossRef]

68. Dhayat, S.A.; Mardin, W.A.; Seggewiß, J.; Ströse, A.J. MicroRNA Profiling Implies New Markers of Gemcitabine Chemoresistance in Mutant p53 Pancreatic Ductal Adenocarcinoma. PLoS ONE 2015, 10, e0143755. [CrossRef]

69. Sinn, M.; Sinn, B.V.; Treue, D. TP53 Mutations Predict Sensitivity to Adjuvant Gemcitabine in Patients with Pancreatic Ductal Adenocarcinoma: Next-Generation Sequencing Results from the CONKO-001 Trial. Clin. Cancer Res. 2020, 26, 3732-3739. [CrossRef]

70. Zhang, Q.; Bykov, V.J.N.; Wiman, K.G. APR-246 reactivates mutant p53 by targeting cysteines 124 and 277. Cell Death Dis. 2018, 9, 439. [CrossRef]

71. Cluzeau, T.; Sebert, M.; Rahmé, R.; Cuzzubbo, S. APR-246 Combined with Azacitidine (AZA) in TP53 Mutated Myelodysplastic Syndrome (MDS) and Acute Myeloid Leukemia (AML). a Phase 2 Study By the Groupe Francophone Des Myelodysplasies (GFM). Blood 2019, 134 (Suppl. S1), 677. [CrossRef]

72. Mohell, N.; Alfredsson, J.; Fransson, A. APR-246 overcomes resistance to cisplatin and doxorubicin in ovarian cancer cells. Cell Death Dis. 2015, 6, e1794. [CrossRef] [PubMed]

73. Saha, M.N.; Jiang, H.; Yang, Y. PRIMA-1Met/APR-246 displays high antitumor activity in multiple myeloma by induction of p73 and Noxa. Mol. Cancer Ther. 2013, 12, 2331-2341. [CrossRef] [PubMed]

74. Dixon, H.; Norbury, C.J. Therapeutic exploitation of checkpoint defects in cancer cells lacking p53 function. Cell Cycle 2002, 1, 362-368. [CrossRef] [PubMed]

75. Ma, C.X.; Janetka, J.W.; Piwnica-Worms, H. Death by releasing the breaks: CHK1 inhibitors as cancer therapeutics. Trends Mol. Med. 2011, 17, 88-96. [CrossRef] [PubMed]

76. Nagasawa, H.; Li, C.Y.; Maki, C.G.; Imrich, A.C. Relationship between radiation-induced G1 phase arrest and p53 function in human tumor cells. Cancer Res. 1995, 55, 1842-1846. [PubMed]

77. Leijen, S.; Beijnen, J.H.; Schellens, J.H. Abrogation of the G2 checkpoint by inhibition of Wee-1 kinase results in sensitization of p53-deficient tumor cells to DNA-damaging agents. Curr. Clin. Pharmacol. 2010, 5, 186-191. [CrossRef]

78. Hirokawa, T.; Shiotani, B.; Shimada, M.; Murata, K. CBP-93872 inhibits NBS1-mediated ATR activation, abrogating maintenance of the DNA double-strand break-specific G2 checkpoint. Cancer Res. 2014, 74, 3880-3889. [CrossRef]

79. Mc Gee, M.M. Targeting the Mitotic Catastrophe Signaling Pathway in Cancer. Mediat. Inflamm. 2015, 2015, 146282. [CrossRef]

80. Toledo, L.I.; Murga, M.; Fernandez-Capetillo, O. Targeting ATR and Chk1 kinases for cancer treatment: A new model for new (and old) drugs. Mol. Oncol. 2011, 5, 368-373. [CrossRef] 
81. Sorensen, C.S.; Syljuasen, R.G. Safeguarding genome integrity: The checkpoint kinases ATR, CHK1 and WEE1 restrain CDK activity during normal DNA replication. Nucleic Acids Res. 2012, 40, 477-486. [CrossRef] [PubMed]

82. Xiao, H.H.; Makeyev, Y.; Butler, J. 7-Hydroxystaurosporine (UCN-01) preferentially sensitizes cells with a disrupted TP53 to gamma radiation in lung cancer cell lines. Radiat. Res. 2002, 158, 84-93. [CrossRef]

83. Bridges, K.A.; Hirai, H.; Buser, C.A. MK-1775, a novel Wee1 kinase inhibitor, radiosensitizes p53-defective human tumor cells. Clin. Cancer Res. 2011, 17, 5638-5648. [CrossRef] [PubMed]

84. Hall, A.B.; Newsome, D.; Wang, Y. Potentiation of tumor responses to DNA damaging therapy by the selective ATR inhibitor VX-970. Oncotarget 2014, 5, 5674-5685. [CrossRef] [PubMed]

85. Rajeshkumar, N.V.; Oliveira, E.D.; Ottenhof, N. MK-1775, a potent Wee1 inhibitor, synergizes with gemcitabine to achieve tumor regressions, selectively in p53-deficient pancreatic cancer xenografts. Clin. Cancer Res. 2011, 17, 2799-2806. [CrossRef] [PubMed]

86. Van Linden, A.A.; Baturin, D.; Ford, J.B. Inhibition of Wee1 sensitizes cancer cells to antimetabolite chemotherapeutics in vitro and in vivo, independent of p53 functionality. Mol. Cancer Ther. 2013, 12, 2675-2684. [CrossRef]

87. Leijen, S.; Van Geel, R.M.J.M.; Pavlick, A.C. Phase I Study Evaluating WEE1 Inhibitor AZD1775 As Monotherapy and in Combination With Gemcitabine, Cisplatin, or Carboplatin in Patients With Advanced Solid Tumors. J. Clin. Oncol. 2016, 34, 4371-4380. [CrossRef]

88. Nam, A.R.; Jin, M.H.; Park, J.E. Therapeutic Targeting of the DNA Damage Response Using an ATR Inhibitor in Biliary Tract Cancer. Cancer Res. Treat. 2019, 51, 1167-1179. [CrossRef]

89. Nam, A.R.; Jin, M.H.; Bang, J.H. Inhibition of ATR Increases the Sensitivity to WEE1 Inhibitor in Biliary Tract Cancer. Cancer Res. Treat. 2020, 52, 945-956. [CrossRef]

90. Dillon, M.T.; Boylan, Z.; Smith, D. PATRIOT: A phase I study to assess the tolerability, safety and biological effects of a specific ataxia telangiectasia and Rad3-related (ATR) inhibitor (AZD6738) as a single agent and in combination with palliative radiation therapy in patients with solid tumours. Clin. Transl. Radiat. Oncol. 2018, 12, 16-20.

91. Vassilev, L.T.; Vu, B.T.; Graves, B.; Carvajal, D.; Podlaski, F.; Filipovic, Z.; Kong, N.; Kammlott, U.; Lukacs, C.; Klein, C.; et al. In vivo activation of the p53 pathway by small-molecule antagonists of MDM2. Science 2004, 303, 844-848. [CrossRef] [PubMed]

92. Jones, R.J.; Baladandayuthapani, V. HDM-2 inhibition suppresses expression of ribonucleotide reductase subunit M2, and synergistically enhances gemcitabine-induced cytotoxicity in mantle cell lymphoma. Blood 2011, 118, 4140-4149. [CrossRef] [PubMed]

93. Karni-Schmidt, O.; Lokshin, M.; Prives, C. The Roles of MDM2 and MDMX in Cancer. Annu. Rev. Pathol. 2016, 11, 617-644. [CrossRef]

94. Graves, B.; Thompson, T.; Xia, M. Activation of the p53 pathway by small-molecule-induced MDM2 and MDMX dimerization. Proc. Natl. Acad. Sci. USA 2012, 109, 11788-11793. [CrossRef] [PubMed]

95. Chang, Y.S.; Graves, B.; Guerlavais, V. Stapled alpha-helical peptide drug development: A potent dual inhibitor of MDM2 and MDMX for p53-dependent cancer therapy. Proc. Natl. Acad. Sci. USA 2013, 110, E3445-E3454. [CrossRef]

96. Fan, Y.; Ma, K.; Jing, J.; Wang, C. Recombinant Dual-target MDM2/MDMX Inhibitor Reverses Doxorubicin Resistance through Activation of the TAB1/TAK1/p38 MAPK Pathway in Wild-type p53 Multidrug-resistant Breast Cancer Cells. J. Cancer 2020, 11, 25-40. [CrossRef]

97. Lu, X.; Nguyen, T.A.; Moon, S.H. The type 2C phosphatase Wip1: An oncogenic regulator of tumor suppressor and DNA damage response pathways. Cancer Metastasis Rev. 2008, 27, 123-135. [CrossRef]

98. Gilmartin, A.G.; Faitg, T.H.; Richter, M. Allosteric Wip1 phosphatase inhibition through flap-subdomain interaction. Nat. Chem. Biol. 2014, 10, 181-187. [CrossRef]

99. Wu, C.E.; Esfandiari, A.; Ho, Y.H. Targeting negative regulation of p53 by MDM2 and WIP1 as a therapeutic strategy in cutaneous melanoma. Br. J. Cancer 2018, 118, 495-508. [CrossRef]

100. Esfandiari, A.; Hawthorne, T.A.; Nakjang, S. Chemical Inhibition of Wild-Type p53-Induced Phosphatase 1 (WIP1/PPM1D) by GSK2830371 Potentiates the Sensitivity to MDM2 Inhibitors in a p53-Dependent Manner. Mol. Cancer Ther. 2016, 15, 379-391. [CrossRef] 
101. Pechackova, S.; Burdova, K.; Benada, J. Inhibition of WIP1 phosphatase sensitizes breast cancer cells to genotoxic stress and to MDM2 antagonist nutlin-3. Oncotarget 2016, 7, 14458-14475. [CrossRef] [PubMed]

102. Pechackova, S.; Burdová, K.; Macurek, L. WIP1 phosphatase as pharmacological target in cancer therapy. J. Mol. Med. (Berl.) 2017, 95, 589-599. [CrossRef] [PubMed]

Publisher's Note: MDPI stays neutral with regard to jurisdictional claims in published maps and institutional affiliations.

(C) 2020 by the authors. Licensee MDPI, Basel, Switzerland. This article is an open access article distributed under the terms and conditions of the Creative Commons Attribution (CC BY) license (http://creativecommons.org/licenses/by/4.0/). 